Medicine in the Elderly

\title{
Sexual abuse of the elderly mentally ill
}

\author{
Susan M. Benbow and Peter M. Haddad ${ }^{1}$ \\ York House, Manchester Royal Infirmary, Oxford Road, Manchester M139BX and ${ }^{1}$ CRC Psychological \\ Medicine Group, Stanley House, 553 Wilmslow Road, Withington, Manchester, UK
}

\begin{abstract}
Summary: Sexual abuse of the elderly may occur more commonly than is recognized. Reasons for the neglect of this area and possible risk factors are discussed. A definition of elder sexual abuse is proposed, and four case histories, each of which raises various issues about the nature, detection and management of sexual abuse, are described. In the absence of procedures for dealing with elder sexual abuse, professional staff need to be open to its occurrence and to be prepared to carry out thorough, sympathetic, collaborative assessments of both parties involved where it is suspected.
\end{abstract}

\section{Problems of definition}

Before attempting to define elder sexual abuse it is useful to review the problems in defining the more general term 'elder abuse'. Widely different views exist on what constitutes abuse $\mathrm{e}^{1-3}$ and as yet there is no universally accepted definition. The central dilemma is that elder abuse is an elastic term, covering a wide variety of presentations, from a relative who repeatedly batters an elderly person to society failing to provide sufficient community care for their elders. ${ }^{4}$

There are four key issues in definition. Firstly, what areas should be included within definitions of abuse? Eastman ${ }^{5}$ considered elder abuse as the systematic maltreatment, physical, emotional or financial, of an elderly person by a care-giving relative', and included within this definition 'sexual assault', as a form of physical abuse. Most definitions include physical, emotional and financial abuse but do not mention sexual abuse. ${ }^{6}$ Secondly, should abuse encompass neglect, and, if so, what types of neglect, for example, active and passive neglect by carers, self-neglect? The inclusion of self-neglect has been criticized on the grounds that it does not represent maltreatment by a carer but instead society's failure to meet the needs of its elderly members. , $^{2,3,8}$ Thirdly, should abuse only refer to acts between elderly people and those people in relationships with them or should it extend to include formal carers, acquaintances outside the family and even strangers? Some definitions ${ }^{5}$ include only care-giving relatives, others include the possibility of abuse by non-

Correspondence: S.M. Benbow, M.R.C.Psych. Accepted: 14 April 1993 relatives, such as professional care staff,,$^{2,9-11}$ and Pritchard ${ }^{12}$ has noted that the main types of abuse can all occur in institutional settings. Finally, should there be thresholds for the frequency and severity of acts which are considered abusive?

For clinical purposes the concept of inadequate care $^{13}$ overcomes many of these problems, but for research purposes an operational definition is needed. If elder abuse definitions are not always appropriate, are there useful parallels in work with childhood sexual abuse which could be taken and applied in work with older people? There are various definitions of sexual abuse in children, for example, 'any form of coerced sexual interaction between an individual and a person in a position of power over that individual', ${ }^{14}$ and 'when (an) .. . adult on whom the child depends uses his or her authority ... so as to meet their own sexual needs'. ${ }^{15}$ It may be more difficult to include the notion of power or authority in work with older people, and in this article we define elder sexual abuse as occurring when an individual has a physical sexual relationship with an elderly person without that person's informed consent, excluding sexual assaults by complete strangers. 'Physical sexual relationship' refers not only to intercourse but to other forms of intimate sexual contact, such as touching the genital areas. This is an arbitrary definition, and includes acts perpetrated by noncarers, unlike some definitions referred to earlier.

\section{A neglected topic}

Little has been written about the sexual abuse of older people and detection is the first hurdle: ${ }^{16}$ 
Eastman ${ }^{17}$ stated that he had only personally come across two cases of sexual abuse and McCreadie and Tinker ${ }^{18}$ state that it appears to be rare. Ogg ${ }^{19}$ stated that it should be regarded as a possibility. Kimsey et al. ${ }^{20}$ stated that homosexual and heterosexual abuse of the aged may be much more frequent than is generally recognized, because of under-reporting, but provided no evidence. Bennet $^{21}$ listed the possible physical indicators of sexual abuse in older people on examination. Possible reasons for this neglect include the following:

1. Elder abuse in general has only recently come to public attention. Bennett ${ }^{22}$ pointed out that child and spouse abuse received attention in the 1960s and 1970s, respectively, but only in the 1980s did elder abuse become an acknowledged problem.

2. The elderly have been portrayed as having no interest in sex. ${ }^{23}$ Researchers may not have considered the possibility that elderly people could have peers who might sexually abuse them, because of the stereotype of sexless older people. In reality, research has shown that there is no upper limit to sexual activity and a significant proportion of older people remain sexually interested and active. ${ }^{24}$

3. Sexuality in late life is a taboo area. ${ }^{23}$

4. In other forms of elder abuse both abuser and victim tend to deny that it has occurred. Recognized cases are likely to be only a small proportion of those occurring. ${ }^{6,25}$ Victims frequently fear reprisals or removal from their home. It is likely that reluctance to admit abuse might be even more marked when it is of a sexual nature. This might partly reflect elderly people internalizing society's stereotype of them as sexless and partly embarrassment of having grown up at a time when people where far less open about discussing sexuality.

5. Sexual involvement outside marriage was regarded in a negative light when many of today's older people grew up and some unmarried women were placed in institutions after becoming pregnant. Cognitively impaired older people may have active memories of such times and therefore be unlikely to report sexual abuse.

6. The move towards community care and more open mixing of the sexes in remaining institutions may bring problems to light which formerly would have remained hidden.

\section{Risk factors}

There are several reasons why the elderly might be more susceptible to sexual abuse. They may be weak and frail and physically unable to resist unwanted sexual advances. They may live in institutions with inadequate supervision. Finally those with mental illnesses, especially dementia, may be unable to inform others of abuse or may be unaware of being abused, although elderly people $\mathbb{\Phi}$ without mental or physical infirmity may also be $\stackrel{\varrho}{c}$ subject to abuse. ${ }^{26}$

We present below four case histories, where $\stackrel{\overrightarrow{\bar{S}}}{\overrightarrow{7}}$ sexual abuse was suspected, and which illustrate $\overrightarrow{0}$ key issues in assessment and management. The case $\frac{\bar{O}}{\sigma}$ histories are classified by the relationship between $\frac{\bar{\rho}}{\square}$ the individuals involved, a system which we have $\overparen{\Phi}$ previously proposed as a useful framework for sexual problems in the elderly mentally ill in general. ${ }^{27}$

\section{Problems independent of a sexual partner}

\section{Case history 1: $\mathrm{Mr} G$}

Mr G was a 62-year-old man who was admitted to a $\%$ continuing care psychogeriatric ward from an ${ }^{\omega}$


behaviour which continued despite trials of depot $\vec{\overrightarrow{ }}$ and oral neuroleptics and which included exposing himself, masturbating in public areas, and $\frac{\vec{O}}{\circ}$ urinating and defaecating indiscriminately over $\stackrel{\mathbb{Q}}{-}$ people's belongings and food. He was known $\overrightarrow{0}$ abuse alcohol and had been diagnosed as having $\notin$ pre-senile dementia 4 years earlier. On the was these behaviours continued: he would sexualfy touch staff and patients, often forcefully. On one occasion he was found in bed with a severely demented woman attempting to have sexual intercourse with her against her will. Staff felt he was sexually abusing other patients and he was sedated $\overline{\overrightarrow{ }}$ heavily whilst the possibility of treatment with an anti-androgen was discussed. He died a few months later of bronchopneumonia.

\section{Case history 2: Mrs B}

Mrs B was an 84-year-old widow who lived in a rest home. She was disabled by rheumatoid arthritis, cognitively impaired and deaf. She had been admit-

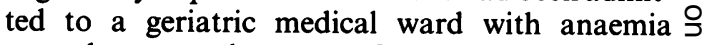
secondary to the use of non-steroidal anti- $\rightarrow$ inflammatory agents. She expressed to the nursing staff ideas which led them to suspect that she had $N$ been sexually abused by a male carer at the home. Medical staff were concerned that she could be misinterpreting events at the home and did not $\omega$ want to take action without good grounds.

Mrs B had told nursing staff that a particular 0 carer 'puts his hand right in ... I don't like it.' She could not understand why it happened as she was a ? widow and knew she was too old to have children. She said he washed her 'privates', making her sore and distressing her. She did not want to 'mess' with 
him, and felt that it would get her 'a bad name'. She had been bathed by various nurses, including male nurses, whilst on the ward and had expressed no discomfort or anxieties about this.

After discussion between geriatric, psychiatric and social services staff, Mrs B was offered a place at another home and moved there. There was no proof of abuse and no action could be taken in relation to whatever had happened at the original rest home.

\section{Problems involving an established partner}

\section{Case history 3: $\mathrm{Mr}$ and $\mathrm{Mrs} \mathrm{A}$}

Mrs A, an 87-year-old woman, suffered from dementia and insulin-dependent diabetes. She was disorientated in time and place, but could recognize her husband, and needed assistance with activities of daily living. She lived in sheltered housing with her 84-year-old husband, but had short-term care in a geriatric hospital and had told nurses she would like to stay there.

Husband and wife were referred for psychiatric assessment following incidents which had concerned the district nurses, who visited Mrs A regularly. The district nurses reported that once every few weeks they would attend Mrs A in the morning and find her incontinence pads undone and askew. At these times she would appear very tired and would complain that 'he' had been 'in' her all night and that she did not like it. They assumed that the couple had had intercourse, that Mrs A had not given consent, and that this amounted to abuse. The nurses also reported that $\mathrm{Mr}$ A verbally abused his wife, causing her distress, and had hit her across the face once in the presence of a nurse.

When seen $\mathrm{Mr} \mathrm{A}$ was angry, irritable and intrusive. He was highly aroused throughout the interview which complicated the assessment. $\mathrm{He}$ refused to discuss his relationship with his wife. $\mathrm{He}$ showed no evidence of functional psychiatric illness, nor of a dementing syndrome, and, after hearing from relatives an account of his previous personality and behaviour, it seemed likely that he had a lifelong personality disorder, characterized by sudden mood changes, aggression, jealousy and difficulty in interpersonal relationships.

Meetings of all staff involved with the couple led an an agreement to document any instances of possible abuse. If there were grounds, the plan was to reconvene and consider a Guardianship Order for Mrs A in order to allow her to move into care. Before reaching this stage, however, his children persuaded $\mathrm{Mr}$ A to move with his wife into a nursing home, outside the city, where they could both be looked after.

\section{Problems involving a new sexual partner}

\section{Case history 4: $M r$ L and Mrs C}

Mr L, a 79-year-old widower, was first referred to the old age psychiatry service in 1985 with multiinfarct dementia. At that time it was reported by the general practitioner and his family that he had made sexual advances towards his daughter-in-law and grand-daughters. In the clinic he tried to kiss nurses and asked a nun (escorting another patient) if she was courting. In 1986 he moved to live in an elderly persons' home, where outbursts of aggression occurred and sexual behaviours continued. He was observed to touch women residents sexually and to make suggestive comments to them. At times staff observed him to be sexually aroused. By 1987 he had established a relationship with another resident of the home, a woman with Alzheimer's disease (Mrs C). Staff reported that she consented to his approaches. They were allowed privacy and spent time on their own together in their bedrooms when staff believed that they had intercourse by mutual consent. Mr L's indiscriminate sexual approaches to other women became less prominent at this time.

Staff were, however, divided on whether Mrs C was able to consent and whether they were fulfilling their care roles in allowing the relationship to continue. Was Mr L taking advantage of Mrs C's vulnerability, even though she appeared to be consenting and enjoying the relationship? When Mrs C's family (who had complained previously about her care in other homes) arrived to visit and just avoided finding their mother and $\mathrm{Mr} \mathrm{L}$ undressed together in the bedroom, the officer-incharge decided that the relationship must be discouraged. Mr L's behaviour was soon reported to be more disturbed and he was subsequently treated with a major tranquillizer in an attempt to contain both aggression and sexual disinhibition. In 1990 the home closed and the couple moved to separate homes. By this stage he had, however, deteriorated following a series of small strokes, and he died soon afterwards.

\section{Discussion}

The cases illustrate the difficulty of establishing whether sexual abuse has occurred. Case 1 is the only one where abuse, according to our proposed definition had definitely taken place; staff had observed $\mathrm{Mr} \mathrm{G}$ attempting to have intercourse/ intimate sexual contact with elderly women without their consent. In the remaining cases, although suspected, abuse could not be proven. In all four cases the victim was cognitively impaired and could not give detailed accounts of what had taken place, 
even had they wished to do so. Clarifying what has occurred may be less problematic when elderly people are involved who are functionally ill or psychiatrically well. In our cases behavioural signs were the first clue, as Taler and Ansells have suggested. ${ }^{28}$

It is not necessary to prove abuse prior to offering help. If sexual abuse within a marriage is suspected, then marital/family therapy could be offered for 'relationship problems'; this represents an attempt to find a way in to help rather than collusion with the abuse. If either or both partners are cognitively impaired, respite admissions or a move to a more highly supervised living environment might be appropriate as in case 3 . Where there are good grounds to suspect serious abuse it might be appropriate to consider the use of legal powers such as guardianship orders.

Another feature of these cases is that the suspected 'abusers' often have psychiatric problems. In cases 1 and 4 the 'abusers' both had dementing illnesses and a range of problems in addition to the sexual behaviour. Similarly, in case 3 the husband had a personality disorder. It might be helpful to regard both people involved as victims of their illnesses/disorders and in need of help. It is interesting that a high prevalence of psychiatric problems is being increasingly recognized in other forms of elder abuse. ${ }^{29,30}$

Assessment of suspected sexual abuse should be thorough and multi-disciplinary. Non-sexual acts should not be misinterpreted, for example, a demented person may climb into another's bed by mistake, or a man might be found with his trousers down because he has just emerged from the toilet and forgotten to pull them up.

Attempting to understand the context of the abuse will lead to logical and personalized treatment. This is particularly important for demented abusers. Boredom and lack of social contacts may leave sexual contact as one of the few opportunities which a demented person has to display a need for warmth and company. A daily activity programme may benefit such an individual. Some people might respond to simple repeated explanations that certain behaviours are not acceptable. Anti-libidinal drugs can be considered as a last resort for severe sexual disinhibition in demented men, but there is little information on their efficacy in this group, ${ }^{30}$ and they should be used in combination with social and psychological treatments. Several antilibidinal drugs have been used in general psychiatry but only cyproterone acetate is licensed for use in the UK. Ethical dilemmas are raised by the use of these drugs in any setting. Demented people may not be able to consent to take them and may not be able to inform staff of any side effects. Good practice might involve including the next of kin in the decision to use an anti-libidinal drug, even though a relative cannot, in law, give consent on behalf of an adult with dementia. ${ }^{31}$ Regular medical $\bar{z}$ and nursing supervision and serial laboratory $\stackrel{\mathbb{Q}}{\stackrel{2}{2}}$ investigations are necessary to screen for potential $c$. drug side effects.

In case 4 Mrs $\mathrm{C}$ did not object to Mr L's sexual advances, but their relationship could be regarded as abusive if Mrs $\mathrm{C}$ were unable to give consent. Lichtenberg and Strzepek ${ }^{32}$ have suggested guidelines for the assessment of the competency of $\stackrel{\mathbb{2}}{2}$ a person with dementia to engage in an intimate $\%$ relationship. They put forward three considera- $\vec{\circ}$ tions: the person's awareness of the relationship, their ability to avoid exploitation, and their $\vec{\omega}$ awareness of possible risks. If these are used $\frac{\rho}{\circ}$ sensitively and with flexibility they may be helpful in assessing possible sexual abuse and sexual relationships in elderly people with dementia of generally. ${ }^{30}$ The concept of substituted judgement may be relevant here: what would that individual $\sigma$ have chosen to do, had they been capable of ${ }^{\infty}$ making a choice? Would Mrs C's behaviour have been consistent with her previous beliefs and values? Would she have had the capacity to say no to a sexual relationship with $\mathrm{Mr} \mathrm{L}$ ? If the answers to these questions are no, then she could be considered incompetent to consent and the staff's role should have been to protect her from exploitæ $\vec{\varphi}$ tion. This raises another complex issue, that of sta attitudes towards sexuality in late life and the nee for training and discussion of how to deal with sexual problems. Staff making these decisions often feel vulnerable because of uncertainties about the rights of people with dementias, their own duties and procedures to follow, as illustrated by the divided attitudes of staff in case 4 . To prevent competent individuals from participating in a sexual relationship might be viewed as another form of elder sexual abuse, although outwith our proposed definition. These dilemmas are probably more overt in today's open climate; in the past institutions would decide what was appropriate or inappropriate for people without decisions being questioned. ${ }^{33}$

There are parallels between the abuse of vulnerable elderly people and the abuse of children, but, in childcare, procedures have been established and modified so that professionals are clear about their duties and responsibilities. In the USA there are laws which govern elder abuse, ${ }^{34}$ although they may have been inconsistent ${ }^{35}$ and limited. ${ }^{2}$ In the UK the field is less advanced.

We need to set ourselves four goals:

1. To develop an accepted definition of elder sexual abuse.

2. To recognize the possibility of sexual abuse of vulnerable old people by their peers and carers.

\section{(1)}


3. To establish ethical guidelines for the consent of cognitively impaired old people to sexual relationships - without guidelines carers risk colluding with abuse whether they allow or prevent a sexual relationship.

4. To develop procedures to deal with elder sexual abuse.

\section{References}

1. Johnson, T. Critical issues in the definition of elder mistreatment. In: Pillemer, K. \& Wolf, R. (eds) Elder Abuse: Conflict in the Family. Auburn House, Dover, MA, 1986.

2. Salend, E., Kane, R.A., Satz, M. \& Pynoos, J. Elder abuse reporting: limitations of statutes. Gerontologist 1984, 24: $61-69$.

3. Family Research Laboratory. Elder Abuse and Neglect: Recommendations from the Research Conference on Elder Abuse and Neglect. University of New Hampshire, Durham, NH, 1986 (unpublished manuscript).

4. Pitt, B. Abusing old people. Br Med J 1992, 305: 968-969.

5. Eastman, M. What is old age abuse? In: Old Age Abuse. Age Concern, Mitcham, 1984, pp. 23-33.

6. Pillemer, K. \& Finkelhor, D. The prevalence of elder abuse: a random sample survey. Getontologist 1988, 28: 51-57.

7. Callahan, J.J. Elder abuse programming: will it help the elderly? Urban Social Change Rev 1982, 15: 15-19.

8. Crystal, S. Social policy and elder abuse. In: Pillemer, K. \& Wolf, R. (eds) Elder Abuse: Conflict in the Family. Auburn House, Dover, MA, 1986.

9. Bourland, M.D. Elder abuse. From definition to prevention. Postgrad Med J 1990, 87: 139.

10. Clark, C.B., Geriatric abuse intervention team in a family practice setting. J Tennessee Med Assoc 1984, 77: 535-536.

11. Thobaben, M. \& Anderson, L. Reporting elder abuse: it's the law. Am J Nursing 1985, 85: 371-374.

12. Pritchard, J. Recognising abuse. In: Pillemer, K. \& Wolf, R. (eds) The Abuse of Elderly People. A Handbook for Professionals. Jessica Kingsley Publishers, London, 1992, pp. 27-40.

13. Fulmer, T.T. \& O'Malley, T.A. Inadequate Care of the Elderly. Springer, New York, 1987.

14. Dolan, Y.M. The legacy of abuse. In: Resolving Sexual Abuse. Solution Focused Therapy and Eriksonian Hypnosis for Adult Survivors. WW Norton \& Co, London, 1991, pp. 1-23.

15. NSPCC. Breaking Through (Identifying Child Sexual Abuse). NSPCC, 1985.

16. JAMA. The elderly: newest victims of familial abuse. JAMA 1980, 243: $1221-1225$.

17. Eastman, M. Signs and symptoms. In: Old Age Abuse. Age Concern, Mitcham, 1984, pp. 57-68.

18. McCreadie, C. \& Tinker, A. Review: abuse of elderly people in the domestic setting: a UK perspective. Age Ageing 1993, 22: $65-69$.

\section{Acknowledgement}

We would like to thank Bob Baldwin for agreeing to the inclusion of details about patients who were under his care for part of their contact with the old age psychiatry service.

19. Ogg. J. Elder sexual abuse - the last taboo? Geriatric Med 1992, 22: 10 .

20. Kimsey, L.R., Tarbox, A.R. \& Bragg, D.F. Abuse of the elderly - the hidden agenda 1 . The caretakers and the categories of abuse. J Am Geriatrics Soc 1981, 29: 465-472.

21. Bennett, G.C.J. Shifting emphasis from abused to abuser. Geriatric Med 1990, 20: 45-47.

22. Bennett, G. Assessing abuse in the elderly. Geriatric Med 1990, 20: 45-47.

23. Pfeiffer, E. Sexual behaviour in old age. In: Busse, E.W. \& Pfeiffer, E. (eds) Behaviour and Adaptation in Late Life. Little, Brown, Boston, 1977.

24. White, C.B. Sexual interests, attitudes, knowledge and sexual history in relation to sexual behavior in the institutionalised aged. Arch Sexual Behav 1982, 11: 11-21.

25. Haddad, P.M. \& Benbow, S.M. Abuse of elderly people. $\mathrm{Br}$ Med J 1992, 305: 1363.

26. Eastman, M. The battered elderly. In: Old Age Abuse. Age Concern, Mitcham. 1984, pp. 34-41.

27. Haddad, P.M. \& Benbow, S.M. Sexual problems associated with dementia: part 1: problems and their consequences. Int $J$ Geriatric Psychiatry 1993, 8: 547-551.

28. Taler, G. \& Ansells, E.F. Elder abuse. Am Family Physician 1985, 32: $107-114$

29. O'Malley, T.A., O'Malley, H.C., Everitt, D.E. \& Sarson, D. Categories of family-mediated abuse and neglect of elderly persons. J Am Geriatrics Soc 1984, 32: 362-369.

30. Haddad, P.M. \& Benbow, S.M. Sexual problems associated with dementia: part 2: Aetiology, assessment and treatment. Int J Geriatric Psychiatry (in press).

31. Law Commission. Mentally Incapacitated Adults and Decision Making: an Overview. Law Commission, consultation paper 119. HMSO, London.

32. Lichtenberg, P.A. \& Strzepek, D.M. Assessment of institutionalised dementia patients' competencies to participate in intimate relationships. Gerontologist 1990, 30: 117-120.

33. Gordon, R.A. Decision making and mental incapacity. EAGLE: Exchange on Ageing, Law \& Ethics 1993, 1: 11-13.

34. Riffer, J. Elder abuse victims estimated at 1 million. Hospitals 1985, 59: 60.

35. Wolf, R.S. Elder abuse: ten years later. J Am Geriatrics Soc 1988, 36: 758-762. 